\title{
Pulmonary Tuberculosis in Morocco: A Two Year Retrospective Study*
}

\author{
Hanaa Mouchrik ${ }^{1 \#}$, Abdelmajid Soulaymani' ${ }^{1}$, Mhammed Jabri², Hinde Hami' \\ Abdelrhani Mokhtari ${ }^{1}$
}

${ }^{1}$ Laboratory of Genetics and Biometry, Faculty of Science, Ibn Tofail University, Kenitra, Morocco

${ }^{2}$ Diagnostic Center of Tuberculosis and Respiratory Diseases, Kenitra, Morocco

Email: \#hanaa87@gmail.com

How to cite this paper: Mouchrik, $\mathrm{H}$. Soulaymani, A., Jabri, M., Hami, H. and Mokhtari, A. (2018) Pulmonary Tuberculosis in Morocco: A Two Year Retrospective Study. Journal of Tuberculosis Research, 6 , 104-111.

https://doi.org/10.4236/jtr.2018.61010

Received: January 7, 2018

Accepted: March 26, 2018

Published: March 29, 2018

Copyright $(9) 2018$ by authors and Scientific Research Publishing Inc. This work is licensed under the Creative Commons Attribution International License (CC BY 4.0).

http://creativecommons.org/licenses/by/4.0/

\begin{abstract}
OBJECTIVES: To determine the epidemiological features of pulmonary tuberculosis in the region of Gharb-Chrarda-Beni-Hssen in Morocco. METHODS: This is a retrospective study of pulmonary tuberculosis cases, diagnosed and treated at the regional diagnostic center of tuberculosis and respiratory diseases (RDCTRD) in Kenitra between January 2010 and December 2011. RESULTS: During the study period, there were 456 cases diagnosed with pulmonary tuberculosis at the RDCTRD, accounting for $51.3 \%$ of all tuberculosis cases reported during this period. More than two-thirds were men (69\%), with a male-female ratio of 2.22 and $3.3 \%$ of cases were children under the age of 15 years. The average age of the patients was $37.07 \pm 0.78$ years. The average body weight at diagnosis of tuberculosis was $56.20 \pm 0.55 \mathrm{~kg}$ for all patients. According to the results, $89 \%$ of pulmonary tuberculosis cases were microscopically positive. The majority of patients $(80.3 \%)$ showed signs of tuberculous impregnation. Nearly three-quarters of these cases (71\%) were smokers, $21 \%$ were cannabis addicts and $7 \%$ were alcoholics. Among the 427 cases for whom the outcome was known, $3(0.7 \%)$ of them died. CONCLUSION: Tuberculosis can be controlled by preventing transmission and infection, by stopping the progression from latent infection to active tuberculosis, and by treating active disease.
\end{abstract}

\section{Keywords}

Pulmonary Tuberculosis, Infection, Epidemiology, Retrospective Study Morocco

\section{Introduction}

Tuberculosis (TB) is a major public health problem worldwide. It is an airborne

${ }^{*}$ This research is conducted as part of the project: PPR-B-Mokhtari-FS-ITU-Kenitra. 
infectious disease caused by Mycobacterium tuberculosis that usually affects the lungs. Nearly one-third of the world's population has latent TB infection [1].

Tuberculosis is one of the top 10 causes of death in the world. Every second, a new person in the world is infected with Koch's bacillus. According to the World Health Organization (WHO), every year, about $1 \%$ of the world's population is newly infected with Mycobacterium tuberculosis and nearly 9 million people develop the disease. In 2015, 1.8 million deaths were registered [2]. Africa is the only continent where the incidence of tuberculosis is estimated to be rising, with 1500 deaths every day. Children are the first victims of this disease [3].

In 2006, WHO recommended the Stop TB Strategy to reduce the global burden of TB by 2015 in line with the Millennium Development Goals (MDGs) and the Stop TB partnership targets [4].

In 2010 , a total of $6000 \mathrm{~TB}$ cases ( 8.2 per 100,000 population) were reported in France.

Pulmonary disease is the most common form of tuberculosis, accounting for $72 \%$ of reported cases [5].

In Morocco, despite considerable efforts deployed and the free tuberculosis treatment, the annual incidence remains high. In fact, 27,000 to 28,000 new cases were reported each year with more than a thousand deaths per year [6].

The present study aims to describe the epidemiological characteristics of pulmonary tuberculosis in the region of Gharb-Chrarda-Béni-Hssen in Morocco.

\section{Material and Methods}

This is a retrospective study of pulmonary tuberculosis cases, diagnosed and treated at the Diagnostic Center of Tuberculosis and Respiratory Disease of Kenitra in Morocco, during the period 2010-2011.

This center is the only one which is located in the region of Gharb Chrarda Beni Hssen in the North West of Morocco.

The climate is Mediterranean, characterized by the alternation between a wet season from October to April and a dry and hot season from May to September. The area of the region is $8805 \mathrm{~km}^{2}$; its population was estimated at $1,859,540$ inhabitants, according to the last General Census of Population and Housing [7].

The data were collected from medical records that contained the necessary information to identify the characteristics of this disease.

The collected data were entered into Excel and analyzed using statistical software.

\section{Results}

During the study period, a total of 456 cases were diagnosed with pulmonary tuberculosis at the RDCTRD (32\% in 2010 and 68\% in 2011), according for $45 \%$ of all tuberculosis cases reported during this period.

The main characteristics of tuberculosis cases are represented in the following Table 1. 
Table 1. Characteristics of tuberculosis cases.

\begin{tabular}{|c|c|}
\hline Characteristics & Number of TB cases (\%) \\
\hline \multicolumn{2}{|l|}{ Provinces } \\
\hline Kenitra & $353(77)$ \\
\hline Sidi Slimane & $103(23)$ \\
\hline Total & $456(100)$ \\
\hline \multicolumn{2}{|l|}{ Sex } \\
\hline Male & $315(69)$ \\
\hline Female & $141(31)$ \\
\hline Total & $456(100)$ \\
\hline \multicolumn{2}{|l|}{ Age groups } \\
\hline Children ( $<15$ years $)$ & $15(3.3)$ \\
\hline Adults ( $\geq 15$ years) & $441(96.7)$ \\
\hline Total & $456(100)$ \\
\hline \multicolumn{2}{|l|}{ Origin } \\
\hline Rural & $210(46.1)$ \\
\hline Urban & $246(53.9)$ \\
\hline Total & $456(100)$ \\
\hline \multicolumn{2}{|l|}{ Profession } \\
\hline Unemployed & $184(42.4)$ \\
\hline Student & $36(8.2)$ \\
\hline Street vendor & $68(15.7)$ \\
\hline Farmer & $46(10.6)$ \\
\hline Private sector & $63(13.8)$ \\
\hline Public sector & $12(2.6)$ \\
\hline Trader & $25(5.8)$ \\
\hline Total & $434(100)$ \\
\hline
\end{tabular}

The distribution of the cases according to their origins showed that $77 \%$ of patients were from Kenitra and 23\% from Sidi Slimane. More than two-thirds of the cases were men (69\%), with a male-female ratio of 2.22 .

Tuberculosis mostly affects adults in their most productive years. However, all age groups are at risk. According to the results, 3.3\% of the cases were children under the age of 15 years.

The average age of the patients was a $37.07 \pm 0.78$ year ranging from 2 to 87 years.

Tuberculosis cases of rural origin accounted for $46.1 \%$ of all cases reported in the region studied and the unemployed were most concerned with $42.4 \%$ of cases (Table 1).

The Table 2 below shows the clinical signs and symptoms of TB infection. 
Table 2. Clinical signs and symptoms of pulmonary tuberculosis.

\begin{tabular}{lc}
\hline \multicolumn{1}{c}{ Signs and Symptoms* } & Number of TB cases (\%) \\
\hline Signs of tuberculous imprégnation & $204(65)$ \\
Fever & $151(48.4)$ \\
Night sweats & $137(43.4)$ \\
Weight loss & $99(31.7)$ \\
Asthenia & $43(13.8)$ \\
Anorexia & $263(57.6)$ \\
Cough & $49(15.7)$ \\
Hémoptysis & $24(7.7)$ \\
Chest pain & $4(1.3)$ \\
Dyspnea & $4(1.3)$ \\
Vomiting & $3(0.9)$ \\
Others &
\end{tabular}

*The total number of clinical signs and symptoms reported is greater than the total number of TB cases, because the majority of cases show the combination of several signs.

According to the results, $80.3 \%$ of patients showed signs of tuberculous impregnation. TB patients usually presented with fever (65\%), weight loss (43.4\%), night sweats (48.4\%), asthenia (31.7\%) and anorexia (13.8\%). Other clinical signs and symptoms were reported.

Cough (57.7\%), hemoptysis (15.7\%), chest pain (7.7\%), dyspnea (1.3\%), vomiting (1.3\%) and abdominal pain (0.3\%) (Table 2).

Among the 456 cases diagnosed with pulmonary TB at the RDCTRD, 8.4\% were previously treated for tuberculosis.

The majority of pulmonary TB cases reported (89\%) were microscopically positive and $9.5 \%$ were microscopically negative. Only $1.5 \%$ of the cases had a primary pulmonary TB infection.

Toxic habits are shown in the Figure 1 below.

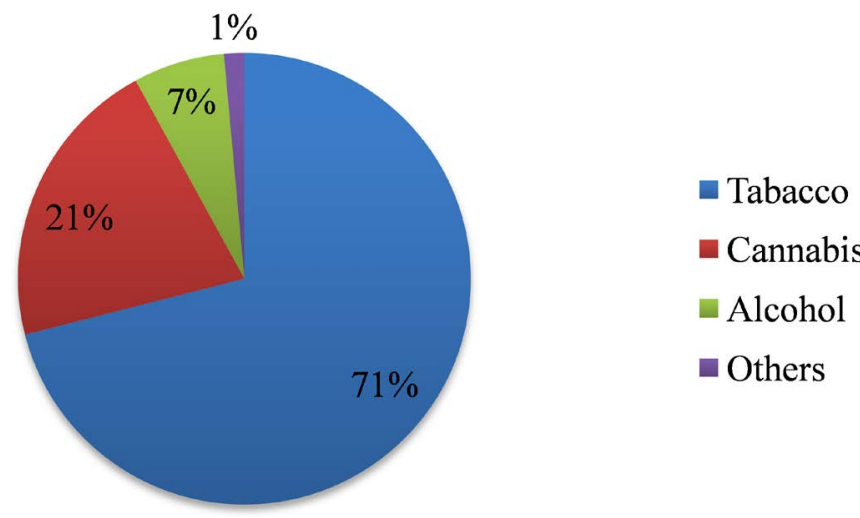

Figure 1. Distribution of pulmonary TB cases according to their toxic. 
We found that $71 \%$ of the patients were smokers, $21 \%$ were cannabis addicts and $7 \%$ were alcoholics (Figure 1).

The Table 3 below summarizes the diseases associated with pulmonary tuberculosis in patients.

Table 3. Diseases associated with pulmonary tuberculosis.

\begin{tabular}{cc}
\hline Associated diseases & Number of TB cases (\%) \\
\hline Diabetes & $38(8.3)$ \\
Arterial hypertension (AHT) & $2(0.4)$ \\
Psychic troubles & $4(0.4)$ \\
Heart disease & $3(0.7)$ \\
Asthma & $2(0.4)$ \\
HIV & $1(0.2)$ \\
Anemia & $1(0.2)$ \\
Paralysis & $1(0.2)$ \\
COPD & \\
Gastritis & $1(0.2)$ \\
Depression & $1(0.2)$ \\
Renal insufficiency & $1(0.2)$ \\
Hypercholesterolemia & $1(0.2)$ \\
Chronic bronchitis & $1(0.2)$ \\
\hline
\end{tabular}

${ }^{\star}$ Human Immunodeficiency Virus; ${ }^{* *}$ Chronic Obstructive Pulmonary Disease.

Among pulmonary tuberculosis patients, we found 38 cases of diabetes (type 1 and type 2).

Several other diseases were reported: psychic troubles (4 cases), heart disease ( 3 cases), arterial hypertension ( 2 cases), asthma ( 2 cases) and HIV (one case) (Table 3).

The mean delay in diagnosis of pulmonary tuberculosis (duration between the onset of symptoms and TB diagnosis) was 57.20 days (range 1 - 365 days).

According to the results, the average body weight at diagnosis of tuberculosis was $56.20 \pm 0.55 \mathrm{~kg}$ for all patients, with a range from 11 to $97 \mathrm{~kg}$.

The treatment outcome of pulmonary tuberculosis cases is represented in the following Figure 2.

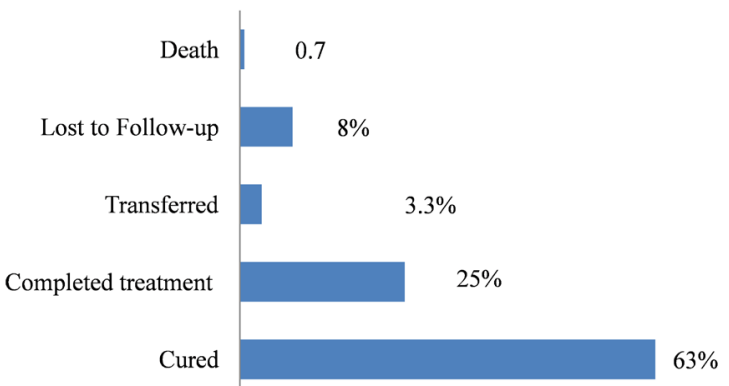

Figure 2. Treatment outcome of pulmonary tuberculosis patients $(\mathrm{N}=427)$. 
Among patients with available information, $63 \%$ were successfully treated, $25 \%$ completed their treatment, $8 \%$ were lost to follow-up, $3.3 \%$ were transferred out to other health facilities and $0.7 \%$ died (Figure 2).

\section{Discussion}

Tuberculosis is a major global health problem. More than $95 \%$ of deaths from this disease occur in low- and middle-income countries [8]. Each year, an estimated 9 million new cases of tuberculosis are diagnosed and nearly 2 million people die from the disease around the world [9]. In 2015, 10.4 million people contracted the disease and 1.8 million died (including 0.4 million of people with HIV). Tuberculosis can be treated with an early diagnosis and adequate treatment [10]. According to the World Health Organization (WHO), the diagnosis and treatment of tuberculosis saved an estimated 49 million lives between 2000 and 2015.

In Morocco, tuberculosis is still endemic. The average annual risk of tuberculous infection is around $1 \%$ with regional variations ranging from $0.5 \%$ to $2 \%$ [11].

In our study, 456 cases were diagnosed with pulmonary tuberculosis, accounting for $51.3 \%$ of all tuberculosis cases reported during the study period. Also, in France, pulmonary tuberculosis is the predominant form of tuberculosis (73.6\%) [12].

According to our results, men (69\%) are more affected than women (31\%), as has been shown in many studies [13]. The age distribution of pulmonary TB cases showed that most cases (96.7\%) were aged 15 to 87 years, with an average age of $37.07 \pm 0.78$ years. All age groups are at risk, as has been shown in other studies [1] [14].

Our results show that more than half (54\%) of pulmonary TB patients came from urban areas. This was also found in Tunisia [15]. According to the statement from the Moroccan Ministry of Health, 70\% of TB cases detected in 2011 were concentrated in urban areas, especially around large cities. Men (58\%) were more affected than women (42\%) and most TB cases (70\%) were aged 15 to 45 years.

The World Health Organization estimates that one million children developed tuberculosis in 2015 and 170,000 children died that year of TB (children with HIV were excluded).

Tuberculosis occurs most often in crowded, economically disadvantaged environments where poor hygienic conditions, crowded housing, malnutrition, poor general health are present [16].

Also, the unemployment rate was found to correlate with high TB incidence [15] [17].

According to our results, $8.4 \%$ of the patients were previously treated for pulmonary tuberculosis. In a study conducted in Mayotte Island, $10.4 \%$ of the TB patients had an antecedent of pulmonary tuberculosis [18]. People at high 
risk for TB infection were people with diabetes, chronic renal disease and HIV, migrants and those from disadvantaged socioeconomic backgrounds [19].

Cigarette smoking, alcohol use and other toxic habits can also promote the spread of TB disease, as has been shown in many studies [20]. Smoking increases the risk of tuberculosis infection by four times for smokers exceeding 20 cigarettes per day [21]. In our study, we found that $71 \%$ of the patients were smokers, $21 \%$ were cannabis addicts and $7 \%$ were alcoholics.

In our study, the mean duration between the onset of symptoms and TB diagnosis was about 57 days. In another study, the delay in diagnosis of tuberculosis exceeded 30 days [22]. This delay is probably due to a progressive evolution of symptoms. All patients were treated with a combination of anti-tuberculosis drugs according to the national TB treatment program. Nearly two-thirds of these cases $(63 \%)$ were successfully treated and $0.7 \%$ died. The TB mortality rate has decreased worldwide $41 \%$ since 1990 [3].

Tuberculosis remains a major cause of morbidity and mortality, particularly in developing countries. Tuberculosis can be controlled by preventing transmission and infection, by stopping the progression from latent infection to active tuberculosis, and by treating active disease.

\section{References}

[1] World Health Organization (2012) Global Tuberculosis Report 2012. WHO Report 2012. WHO, Geneva.

[2] World Health Organization (2010) Global Tuberculosis Control Report: Epidemiology, Strategy, Financing. WHO Report 2010. WHO, Geneva.

[3] World Health Organization (2012) Global Tuberculosis Control. WHO Report 2012. WHO, Geneva.

[4] World Health Organization (2010) The Global Plan to Stop TB, 2011-2015. WHO, Geneva.

[5] Che, D. and Antoine, D. (2012) Epidemiology of Tuberculosis. Revue Pratique, 62, 473-478.

[6] Jouhari, N. (2010) Tuberculosis: 2600 Cases per Year in Morocco. Maroc Hebdo, 50, 879. (In French)

[7] General Census of Population and Housing (2004) http://www.hcp.ma (In French)

[8] World Health Organization (2017) Global Tuberculosis Report 2017. WHO Report 2017. WHO, Geneva.

[9] World Health Organization (2009) Global Tuberculosis Control: A Short Update to the 2009 Report. WHO, Geneva.

[10] Golub, J.E., Bur, S., Cronin, W.A., Gange, S., Baruch, N., Comstock, G.W., et al. (2006) Delayed Tuberculosis Diagnosis and Tuberculosis Transmission. he International Journal of Tuberculosis and Lung Disease, 10, 24-30.

[11] Minister of Public Health (2014) Epidemiology of Tuberculosis in Morocco. Bull Epidemiol, 6, 2-3. (In French)

[12] Working Group of the Conseil Supérieur d'Hygiène Publique of France (2003) Clinical and Bacteriological Diagnosis of Tuberculosis. Revue des Maladies Respiratoires, 20, 7S34-7S40. (In French) 
[13] Che, D. and Antoine, D. (2011) Epidemiology of Tuberculosis in France in 2008. Med Infectious Diseases, 41, 372-378. (In French)

[14] Pronyk, P.M., Makhubele, M.B., Hargreaves, J.R., Tollman, S.M. and Hausler, H.P. (2001) Assessing Health Seeking Behaviour among Tuberculosis Patients in Rural South Africa. International Journal of Tuberculosis and Lung Disease, 5, 619-627. (In French)

[15] Mtiraoui, A., Soltani, M., Ghannem, H., Letaief, M., Zayani, R., Hdhiri, H., et al. (1998) Epidemiology of Tuberculosis in the Tunisian Sahel. Médecine et Maladies Infectieuses, 28, 199-202. (In French) https://doi.org/10.1016/S0399-077X(98)80008-5

[16] Emmanuelli, X. and Grosset, J. (2003) Tuberculosis and Poverty. Revue des Maladies Respiratoires, 20, 169-171. (In French)

[17] Mbatchou, B., Diatta, A., Touré, N., Dia Kane, Y., Ba Diop, S., Ndiaye, E., et al. (2008) Clinical, Biological and Radiological Profile of New Cases of Pulmonary Tuberculosis at the University Hospital Center of Fann Dakar. Revue des Maladies Respiratoires, 25, 22-26. (In French) https://doi.org/10.1016/S0761-8425(08)70462-5

[18] Woessner, J., Receveur, M.C., Malvy, D. and Taytard, A. (2008) Tuberculosis Epidemiology in Mayotte Island. Bulletin De La Societe De Pathologie Exotique, 101, 316-322. (In French) https://doi.org/10.3185/pathexo3184

[19] Horsburgh, C.R. and Rubin, E.J. (2011) Latent Tuberculosis Infection in the United States. The New England Journal of Medicine, 364, 1441-1448.

https://doi.org/10.1056/NEJMcp1005750

[20] Berger, P., Saadjian, M., Gevaudan, M.-J. and Drancourt, M. (2003) Epidemiology of Tuberculosis Documented in Marseille, 1998-2001. Bulletin Épidémiologique Hebdomadaire, 35, 167-168. (In French)

[21] Davies, P.D., Yew, W.W., Ganguly, D., Davidow, A.L., Reichman, L.B., Dheda, K., et al. (2006) Smoking and Tuberculosis: The Epidemiological Association and Immunopathogenesis. Transactions of the Royal Society of Tropical Medicine and $\mathrm{Hy}$ giene, 100, 291-298. https://doi.org/10.1016/j.trstmh.2005.06.034

[22] Gulbaran, Z., Pretet, S. and Dusser, D. (1996) From First Symptom to Diagnosis and from Diagnosis to Treatment of Tuberculosis: Still a Long Delay. Revue De Pneumologie Clinique, 52, 20-25. (In French) 